\title{
Retraction Note: Adenosine triphosphate treatment for supraventricular tachycardia in infants
}

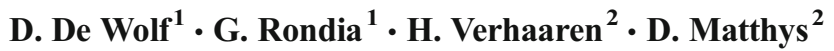

Published online: 7 October 2015

(C) Springer-Verlag Berlin Heidelberg 2015

\section{Retraction Note to: Eur J Pediatr (1994) 153:668-671}

DOI 10.1007/BF02190689

This article, "Adenosine triphosphate treatment for supraventricular tachycardia in infants", published in the European Journal of Pediatrics (1994) 153/9: 668-671, Springer-Verlag 1994 , has been retracted at the request of the Publisher as it is a duplicate of the paper "Adenosine-tri-phosphate treatment for supraventricular tachycardia in infants", that has been published with further corrections in Vol. 153/11: 793-796, of the same journal."

The online version of the original article can be found at http://dx.doi.org/ 10.1007/BF02190689.

D. De Wolf

Daniel.DeWolf@UGent.be

1 Paediatric Cardiology, Department of Paediatrics, University Hospital, Free University of Brussels, Laarbeektaan 101,

B-1090 Brussels, Belgium

2 Paediatric Cardiology, Department of Paediatrics, University Hospital Ghent, Ghent, Belgium 